Original Research Paper

\title{
Investigation of the Characteristics of Thulium Doped Alumina Nanoparticles for Applications in Silica-Based Fibers
}

\author{
Nur Atiqa Bt Rahmat, Hairul Azhar Abd Rashid, H.Y. Wong and Mukter Zaman \\ Faculty of Engineering, Multimedia University, 63100, Cyberjaya, Selangor, Malaysia
}

Article history

Received: 18-09-2016

Revised: $18-01-2017$

Accepted: 20-01-2017

Corresponding Author:

Mukter Zaman

Faculty of Engineering (FOE),

Multimedia University (MMU),

63100 Cyberjaya Selangor,

Malaysaia

Email: mukter@mmu.edu.my

\begin{abstract}
It is reported that during the fabrication of doping RE ions into the silica preform, the distribution of particles is inhomogeneous and becomes uneven throughout the fiber which lead to unwanted spectroscopic characteristics. It is assumed that by using thulium doped with alumina, the problem with the inhomogeneity of the particles inside the fiber can be solved. With the incorporation of alumina particles with thulium ions, the clustering effect and the ion-ion interactions between the ions can be prevented. In this research, thulium doped alumina nanoparticles will be synthesized by using sol-gel method to achieve particles within the nanoscale range of less than $100 \mathrm{~nm}$ in size, evenly distributed nanoparticles and high uniformity. The characterization activities will be perform by using optical microscope, FESEM, EDS and particle analyzer to identify the properties of the resulting solutions. By doping thulium with alumina nanoparticles, it is assumed that the amplification in the transmission systems can be increased and the conversion of passive optical fibers to active fibers can be achieved.
\end{abstract}

Keywords: Thulium, Inhomogeneous, Doping, Nanoparticles, Alumina

\section{Introduction}

In recent years, active elements such as rare earth ions have been used in many optical applications for example in lasers and temperature sensors which allowed very rapid development especially in optical telecommunications industries (Desurvire, 1994; 1995). When the rare earth ions are doped in optical fibers, it can convert the fibers to become active fibers. One of the examples of active fibers that have been used a lot lately is Erbium doped fiber amplifiers or EDFAs. It is known to work in a long range communications and its abilities to simultaneously amplify a few channels in a single fiber that has a high potential to increase the bandwidth for long distance transmission systems. EDFA offers optical amplification over a broad wavelength range from 1530-1600 nm. With the birth of the internet, the growth in the amount of information carried over the transmission systems becomes exponential. Due to the massive increase in bandwidth, the EDFA window for communication has reached its limits. Thus, this increasing demand for bandwidth in the optical fiber communication systems has demanded for a significant research effort into developing efficient and better fiber based optical amplifiers. Thulium is one of the new famous RE elements that are widely used especially in optical fibers. It has a wavelength of 1700-2100 nm which is a suitable wavelength range in the optical amplification research. Thulium has attracted the most attention due to their potential application as optical amplifiers and high powered lasers. But there are some limitations of thulium which are the elements are quite expensive and it suffers from multiphonon nonradiative relaxations when working in silica base environment. The main objectives of this experiment are to investigate synthesis process of thulium doped alumina nanoparticle and to investigate the optimum incorporation process of synthesized nanoparticles in the preform with desired particles size, distribution and uniformity. It is shown that by using thulium doped with alumina nanoparticles, the problem with the inhomogeneity of the particles inside the fiber can be solved (Honzatko et al., 2012). The characterization results of the particle size distribution, surface morphological properties and elemental composition of the nanomaterials are reported.

\section{Organization of the Paper}

The beginning of this paper will be focusing on the methodology to synthesize thulium doped alumina nanoparticles using the sol gel method. The detailed experimental setups and processes will be covered as 
well. The results and discussion with complete tables and figures will be presented at the end of this paper.

\section{Methodology}

\section{Experimental Procedures}

Thulium doped alumina nanoparticles were prepared by using sol gel method which consists of seven steps. Firstly, $0.0002 \mathrm{~mol}$ of thulium chloride hexahydrate $\left(\mathrm{TmCl}_{3} \cdot 6 \mathrm{H}_{2} \mathrm{O}\right)$ was mixed with $0.002 \mathrm{~mol}$ of aluminum chloride hexahydrate $\left(\mathrm{AlCl}_{3} \cdot 6 \mathrm{H}_{2} \mathrm{O}\right)$ and added into $10 \mathrm{ml}$ of distilled water. This solution was labeled as Solution A. The beaker was labeled to avoid confusion with other ongoing solutions. In a different beaker, mixed $5 \mathrm{~mL}$ of Tetraethoxysilane (TEOS) with $5 \mathrm{~mL}$ of ethanol and labeled as Solution B. The solution was mixed vigorously for $10 \mathrm{~min}$ at room temperature. While stirring, $0.81 \mathrm{~mL}$ of Hydrochloric acid $(\mathrm{HCl})$ was added dropwise into Solution $\mathrm{B}$ for another $5 \mathrm{~min}$. This solution was labeled as Solution C. Next, Solution C was added dropwise into Solution A and kept stirring for $2 \mathrm{~h}$ at $60^{\circ} \mathrm{C}$. After a while, the solution will form a gel-like structure. The gel was rinsed with distilled water and centrifuged at $6000 \mathrm{rpm}$ for $5 \mathrm{~min}$. The excess liquid after centrifugation was removed. The steps were repeated for a minimum of 3 times. The resulting precipitate was then heated at $70-100^{\circ} \mathrm{C}$ to obtain thulium doped alumina nanoparticles powder. Figure 1 shows the summaries process of this experiment.

\section{Additional Steps}

Some additional steps were made to improve the results. There are several different methods have been reported to obtain particles within the nanoscale range.

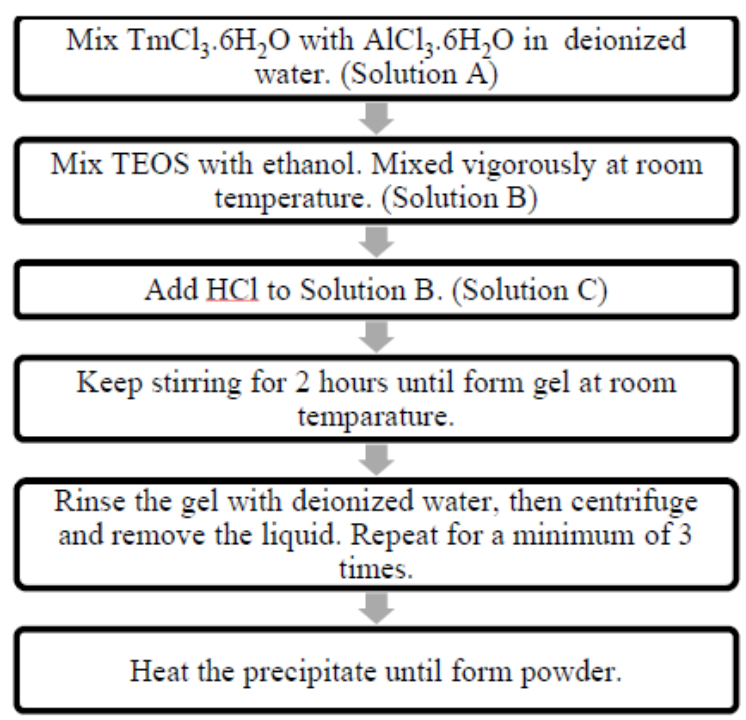

Fig. 1. Summary of Tm doped Al nanoparticles synthesis route
One of the methods is Mechano-Assisted Reduction of Size (MARS) which is a simple method of handgrinding by mortar and pestle. By using this method, particles as small as $20 \mathrm{~nm}$ can be obtained. This is the top-down approach and another way to think about this is "making big stuff smaller". This method was proven by (Blanc et al., 2008), whereby he did a simple hand-grinding of fullerene solids in an agate mortar and pestle. The resulting nanoparticles are found to disperse in water with or without the aid of a dispersing agent Alcatel-Lucent (2007). In order to disperse nanoparticles homogeneously into the solvent, the nanoparticles were carefully prepared by slightly grinding the metal of nanoparticles by hand to smash the agglomerates. This technique enables nanoparticles to disperse uniformly in solvent. The second method to obtain nanosized particles is by sonication. Sonication uses sound energy with frequencies of more than $20 \mathrm{kHz}$ to agitate particles inside a sample Deguchi et al. (2006). It can help to produce even dispersion of nanoparticles in liquid and it is very useful especially when it is not possible to stir the sample. Sonication speeds up the dissolution of particles in solvent by breaking their intermolecular interactions. This method has good influence on the size of distribution of particles. It is commonly performed using an ultrasonic bath. Figure 2 was designed and implemented to all the 28 samples. Firstly, the powder was hand-grinded with pestle and mortar until became fine powder. After that, the powder was diluted using ethanol and stirred well. Next, the solution was sonicated for about $30 \mathrm{~min}$ in ultrasonic bath. The sonicated solution was then heated inside the microwave at $100^{\circ} \mathrm{C}$ for $10 \mathrm{~min}$ until powder was formed.

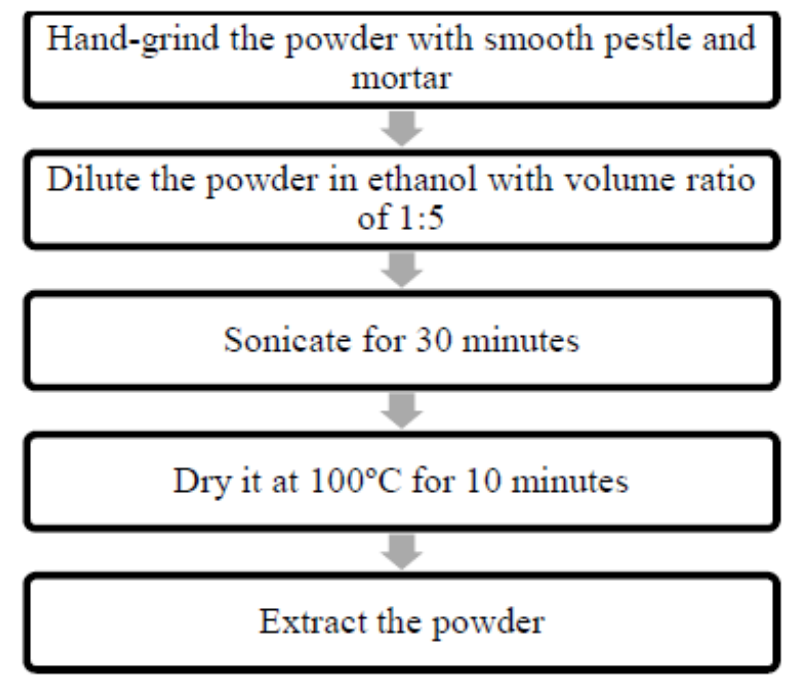

Fig. 2. Additional steps of Tm doped Al nanoparticles 
Table 1. List of concentrations used in the experiment

\begin{tabular}{ll}
\hline Concentration of $\mathrm{TmCl}_{3} \cdot 6 \mathrm{H}_{2} \mathrm{O}(\mathrm{mol})$ & Concentration of $\mathrm{AlCl}_{3} \cdot 6 \mathrm{H}_{2} \mathrm{O}(\mathrm{mol})$ \\
\hline 0.0002 & $0.002,0.004,0.006,0.008,0.010$ \\
0.0004 & $0.002,0.004,0.006,0.008,0.010$ \\
0.0006 & $0.002,0.004,0.006,0.008,0.010$ \\
0.0008 & $0.002,0.004,0.006,0.008,0.010$ \\
0.0010 & $0.002,0.004,0.006,0.008,0.010$ \\
0.0030 & 0.030 \\
0.0070 & 0.070 \\
0.0100 & 0.100 \\
\hline
\end{tabular}

\section{Concentrations of Precursors Used}

Table 1 shows the list of concentrations used in the experiment. There are a total of 28 samples with 3 new samples that were introduced later in this research. The concentrations of the precursors were paired as shown in the table below to investigate the best concentrations based on the results from the characterization techniques. Due to low amount of thulium powder, only 3 new samples can be synthesized which are 3, 7 and 10 mmol of $\mathrm{TmCl}_{3} \cdot 6 \mathrm{H}_{2} \mathrm{O}$.

\section{Methods of Characterization}

The theories and principles related to characterizations and measurements will be presented. After the synthesization of thulium doped alumina nanoparticles, the tasks continued with the characterization of the properties of thulium doped alumina nanoparticles, which include the following characterization work:

1. Particle size: The particle size of the thulium doped alumina nanoparticles was measure by using particle analyzer and optical microscope

2. Topography and elemental information: The topography and elemental information of the thulium doped alumina nanoparticle was scanned using FESEM

3. Elemental composition and distribution: The elemental composition and distribution of the thulium doped alumina nanoparticles was measured by using EDS

Optical microscopy is carried out using the Celestron Penta View digital microscope. Particle size distribution is measured using the Malvern Zetasizer Nano $\mathrm{S}$ dynamic light scattering based particle analyzer. FESEM and EDS characterization is carried out using the Hitachi SU8030 Ultra-High Resolution SEM.

\section{Results and Discussion}

\section{Optical Microscopy Analysis of Tm-Doped Alumina Nanoparticles}

From Table 2 and 3, it can be seen that the particles sizes are approximately less than $100 \mathrm{~nm}$. It was assumed to be little clustering occur in the powder. No serious agglomeration problem was detected. The shapes of the particles are more uniform after the hand-grinding and sonication process. Although the resultant powders are very small in size but it can be seen that there are still some clustering effect occurred. Some of the particles clustered together to form bigger particle which can be seen in concentration 0.6:2, 0.6:4, 0.4:6 and 0.6:8 mmol. This may be due to the incomplete reactions of both hydrolysis and condensation reaction after the gel formation which causes the particles to increase in size (Schmidt and Geiter, 1998). For each concentration, one sample is chosen as the best sample based on their sizes and shapes. As observed, the best samples are when the concentration ratio of $\mathrm{TmCl}_{3} \cdot 6 \mathrm{H}_{2} \mathrm{O}: \mathrm{AlCl}_{3} \cdot 6 \mathrm{H}_{2} \mathrm{O}$ (mmol) to be $0.2: 2,0.4: 4$, $0.6: 6,0.8: 8,1: 10,3: 30,7: 70$ and 10:100.

It can be seen that when the concentrations of $\mathrm{TmCl}_{3} \cdot 6 \mathrm{H}_{2} \mathrm{O}: \mathrm{AlCl}_{3} \cdot 6 \mathrm{H}_{2} \mathrm{O}(\mathrm{mmol})$ is $1: 10$, the shapes of the particles are the most uniform and the sizes are the smallest compared to the rest of the concentrations.

By modifying the samples using both hand-grinding and sonication techniques, it can help to produce even dispersion of the nanoparticles.

\section{FESEM Analysis of Tm-Doped Alumina Nanoparticles}

The three highest concentrations in Table 1 were sent to MIMOS for FESEM and EDS characterizations to observe their characteristics in the nanoscale level. Table 4 shows the topographical information of the nanoparticles after undergoing the additional steps. It can be seen that the distribution of the nanoparticles are uniform with size ranges between $20-50 \mathrm{~nm}$ in diameter. Under the magnification of $200 \mathrm{k}$, it can be seen that the size of the particles are quite uniform although there are still very few clustering effect occurred.

From the magnification figures of $300 \mathrm{k}$, the particles can be clearly observed and measured. Although the concentrations of the precursors were increased, the uniformity of the nanoparticles is still quite high.

\section{EDS Analysis of Tm-Doped Alumina Nanoparticles}

From Table 5, oxygen and silicon have the largest percentage because they were the host environment. Both the oxygen and silicon ions came from the oxidation process and from the sample preparation process respectively. There were some small amounts of contaminants in the samples which were carbon and chlorine. 
Table 2. Optical microscopy results of Tm doped Alumina nanoparticles Concentration of $\mathrm{TmCl}_{3} \cdot 6 \mathrm{H}_{2} \mathrm{O}(\mathrm{mol})$

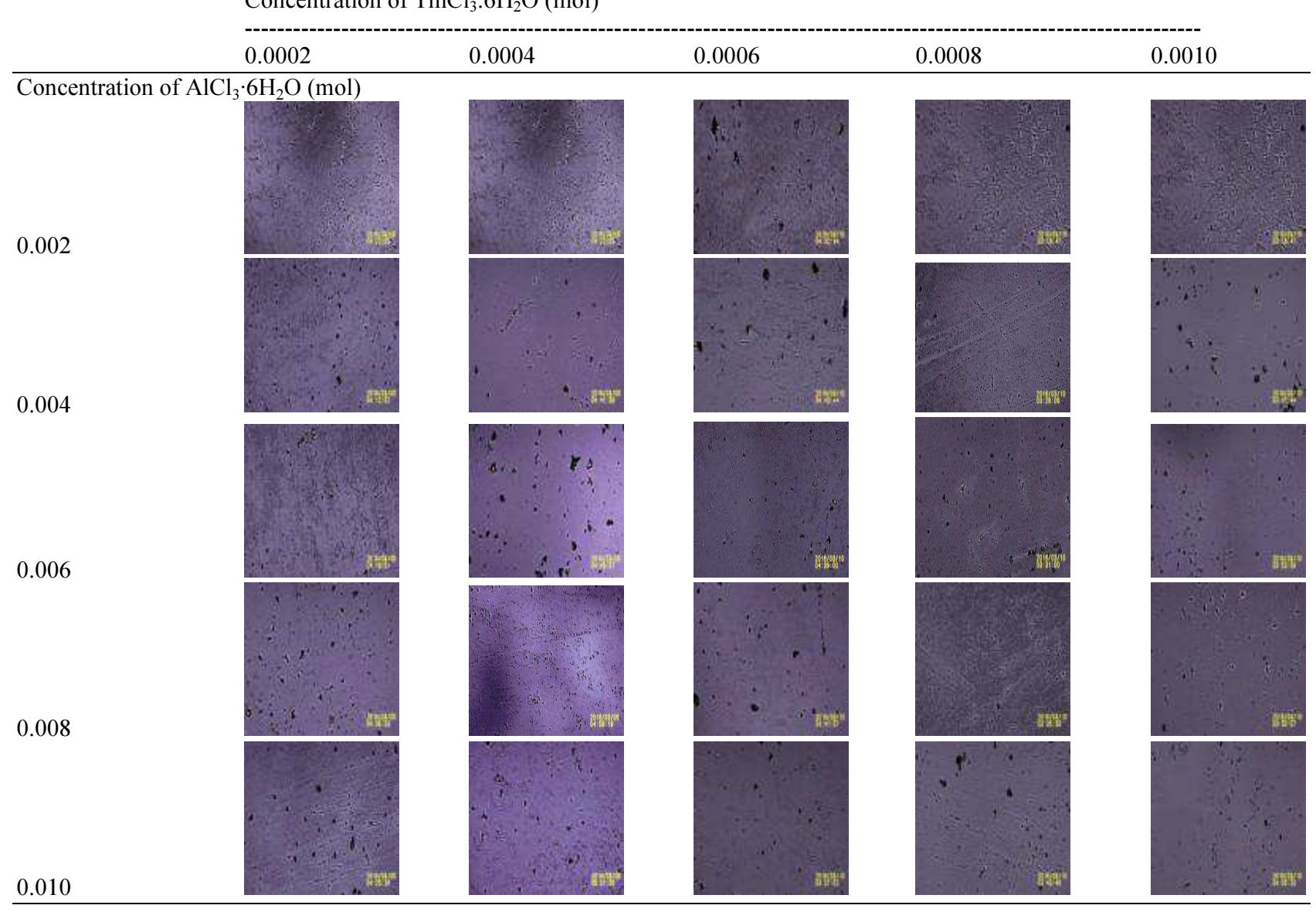

Table 3. Optical microscopy results of the 3 new concentrations of the precursors

\begin{tabular}{lccc}
\hline & $0.0030: 0.030$ & $0.0070: 0.070$ & $0.0100: 0.100$ \\
\hline & & & \\
Concentration of $\mathrm{TmCl}_{3} \cdot 6 \mathrm{H}_{2} \mathrm{O}: \mathrm{AlCl}_{3} \cdot 6 \mathrm{H}_{2} \mathrm{O}(\mathrm{mol})$ & & & \\
\hline
\end{tabular}

Chlorine has the smallest weight percentage among all elements. These contaminants were from the precursor's material which was caused by incomplete reaction. It can be seen that when the concentration for both the precursors increases, the atomic percentage for aluminum and thulium also increases.

\section{Particle Analyzer Analysis of Tm-Doped Alumina Nanoparticles}

As shown in Table 6, the diameter size of the particles varies for each concentration. For example, the concentration ratio of $0.2: 2$ has the lowest diameter size which is $72.24 \mathrm{~nm}$ while for the concentration ratio of $0.2: 4$ is $587.1 \mathrm{~nm}$. Although the difference between the concentrations is not large but the diameter size difference is huge. This is because the diameter size of the agglomerated nanoparticles and individual particles from the dispersed material may be in micrometer range and nanometer range respectively. Hence, the average particle size for the sample will be huge.

Both the average particle size and the particle size distribution are the main parameters to study the dispersions of nanoparticles which are not entirely in monodisperse state and usually consist of numerous distributions.

It can be seen from Table 6-11, the sample with the smallest diameter size particles are when the concentration ratio of $\mathrm{TmCl}_{3} \cdot 6 \mathrm{H}_{2} \mathrm{O}: \mathrm{AlCl}_{3} \cdot 6 \mathrm{H}_{2} \mathrm{O}$ is $1: 10$. Table 12 shows the best samples for each concentration which have both the smallest particle size and PDI value. These samples have PDI values of below than 0.5 and it can be concluded that the samples are monodisperse where most of the particles are of the same size. 
Nur Atiqa Bt Rahmat et al. / American Journal of Applied Sciences 2017, 14 (1): 150.156 DOI: 10.3844/ajassp.2017.150.156

Table 4. FESEM results of Tm doped Alumina nanoparticles Magnification

\begin{tabular}{|c|c|c|c|}
\hline & & & \\
\hline & $10 \mathrm{k}$ & $200 \mathrm{k}$ & $300 \mathrm{k}$ \\
\hline Concent & $6 \mathrm{H}_{2}$ & & \\
\hline $1: 10$ & & & \\
\hline $3: 30$ & & & \\
\hline $7: 70$ & & & \\
\hline $10: 100$ & & & \\
\hline
\end{tabular}

Table 5. EDS results of Tm doped Alumina nanoparticles

\begin{tabular}{|c|c|c|c|c|}
\hline \multirow[b]{2}{*}{ Concentration ratio of $\mathrm{TmCl}_{3} \cdot 6 \mathrm{H}_{2} \mathrm{O}: \mathrm{AlCl}_{3} \cdot 6 \mathrm{H}_{2} \mathrm{O}(\mathrm{mmol})$} & \multicolumn{4}{|c|}{ Atomic percentage $(\%)$} \\
\hline & $1: 10$ & $3: 30$ & $7: 70$ & 10:100 \\
\hline \multicolumn{5}{|l|}{ Elements } \\
\hline Oxygen & 36.32 & 63.76 & 58.53 & 54.06 \\
\hline Silicon & 28.85 & 12.36 & 11.13 & 6.57 \\
\hline Aluminium & 3.85 & 7.24 & 10.16 & 8.03 \\
\hline Thulium & 0.07 & 0.85 & 1.57 & 1.27 \\
\hline
\end{tabular}

$\underline{\text { Table 6. Diameter sizes and PDI values for } 0.2 \mathrm{mmol} \text { of } \mathrm{TmCl}_{3} \cdot 6 \mathrm{H}_{2} \mathrm{O}}$

\begin{tabular}{|c|c|c|c|c|c|}
\hline & \multicolumn{5}{|c|}{ Precursor concentrations $(\mathrm{TmCl} 3 \cdot 6 \mathrm{H} 2 \mathrm{O}: \mathrm{AlCl} 3 \cdot 6 \mathrm{H} 2 \mathrm{O})(\mathrm{mmol})$} \\
\hline & $0.2: 2$ & $0.2: 4$ & $0.2: 6$ & $0.2: 8$ & $0.2: 10$ \\
\hline Size, D (nm) & 72.24 & 587.1 & 670.7 & 980.3 & 1237 \\
\hline PDI & 0.275 & 0.288 & 0.482 & 0.256 & 0.972 \\
\hline
\end{tabular}

Table 7. Diameter sizes and PDI values for $0.4 \mathrm{mmol}$ of $\mathrm{TmCl}_{3} \cdot 6 \mathrm{H}_{2} \mathrm{O}$

\begin{tabular}{|c|c|c|c|c|c|}
\hline & \multicolumn{5}{|c|}{ Precursor concentrations $\left(\mathrm{TmCl}_{3} \cdot 6 \mathrm{H}_{2} \mathrm{O}: \mathrm{AlCl}_{3} \cdot 6 \mathrm{H}_{2} \mathrm{O}\right)(\mathrm{mmol})$} \\
\hline & $0.4: 2$ & $0.4: 4$ & $0.4: 6$ & $0.4: 8$ & $0.4: 10$ \\
\hline Size, D (nm) & 408.0 & 169.2 & 614.8 & 477.5 & 1156.0 \\
\hline PDI & 0.371 & 0.430 & 0.712 & 0.383 & 0.516 \\
\hline
\end{tabular}

Table 8. Diameter sizes and PDI values for $0.6 \mathrm{mmol}$ of $\mathrm{TmCl}_{3} \cdot 6 \mathrm{H}_{2} \mathrm{O}$

\begin{tabular}{|c|c|c|c|c|c|}
\hline & \multicolumn{5}{|c|}{ Precursor concentrations $(\mathrm{TmCl} 3 \cdot 6 \mathrm{H} 2 \mathrm{O}: \mathrm{AlCl} 3 \cdot 6 \mathrm{H} 2 \mathrm{O})(\mathrm{mmol})$} \\
\hline & $0.6: 2$ & $0.6: 4$ & $0.6: 6$ & $0.6: 8$ & $0.6: 10$ \\
\hline Size, D (nm) & 329.8 & 278.6 & 272.7 & 702.7 & 419.1 \\
\hline PDI & 0.326 & 0.280 & 0.314 & 0.486 & 0.359 \\
\hline
\end{tabular}

Table 9. Diameter sizes and PDI values for $0.8 \mathrm{mmol}$ of $\mathrm{TmCl}_{3} \cdot 6 \mathrm{H}_{2} \mathrm{O}$

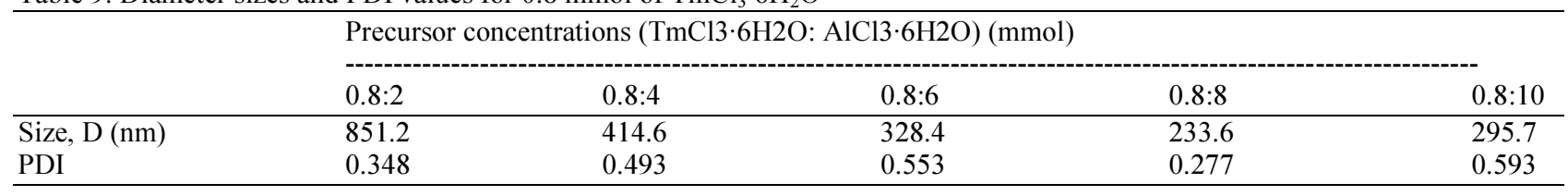


Table 10. Diameter sizes and PDI values for $1 \mathrm{mmol}$ of $\mathrm{TmCl}_{3} \cdot 6 \mathrm{H}_{2} \mathrm{O}$

\begin{tabular}{|c|c|c|c|c|c|}
\hline & \multicolumn{4}{|c|}{ Precursor concentrations $\left(\mathrm{TmCl}_{3} \cdot 6 \mathrm{H}_{2} \mathrm{O}: \mathrm{AlCl}_{3} \cdot 6 \mathrm{H}_{2} \mathrm{O}\right)(\mathrm{mmol})$} & \multirow[b]{2}{*}{$1: 10$} \\
\hline & $1: 2$ & $1: 4$ & $1: 6$ & $1: 8$ & \\
\hline Size, D (nm) & 305.5 & 482.1 & 316.0 & 825.0 & 172.5 \\
\hline PDI & 0.494 & 0.404 & 0.419 & 0.229 & 0.258 \\
\hline
\end{tabular}

Table 11. Diameter sizes and PDI values for 3, 7 and $10 \mathrm{mmol}$ of $\mathrm{TmCl}_{3} \cdot 6 \mathrm{H}_{2} \mathrm{O}$

\begin{tabular}{llll} 
& Precursor concentrations $\left(\mathrm{TmCl}_{3} \cdot 6 \mathrm{H}_{2} \mathrm{O}: \mathrm{AlCl}_{3} \cdot 6 \mathrm{H}_{2} \mathrm{O}\right)(\mathrm{mmol})$ & $10: 100$ \\
\hline Size, D $(\mathrm{nm})$ & $3: 30$ & $7: 70$ & 122.9 \\
PDI & 84.69 & 66.58 & 0.340 \\
\hline
\end{tabular}

Table 12. The best samples for each concentration using particle analyzer

\begin{tabular}{|c|c|c|c|c|c|c|c|c|}
\hline & \multicolumn{7}{|c|}{ Precursor concentrations $(\mathrm{TmCl} 3 \cdot 6 \mathrm{H} 2 \mathrm{O}: \mathrm{AlCl} 3 \cdot 6 \mathrm{H} 2 \mathrm{O})(\mathrm{mmol})$} & \multirow[b]{2}{*}{$10: 100$} \\
\hline & $0.2: 2$ & $0.4: 4$ & $0.6: 6$ & $0.8: 8$ & $1: 10$ & $3: 30$ & $7: 70$ & \\
\hline Size, D (nm) & 72.24 & 169.2 & 272.7 & 233.6 & 172.5 & 84.69 & 66.58 & 122.9 \\
\hline PDI & 0.275 & 0.430 & 0.314 & 0.277 & 0.258 & 0.500 & 0.337 & 0.340 \\
\hline
\end{tabular}

Some of the samples have very high diameter size and high PDI value for example in sample with concentration ratio of $0.2: 10$ and $0.4: 10$. It can be assumed that these samples have serious agglomeration problem as well as the clustering effect.

The main limitation of particle analyzer is that, it only measures the hydrodynamic radius of the particle and not the actual size of the particle Costa et al. (1996). Therefore, data produced can be misleading and not absolute, it should be used in conjunction to other techniques.

In Table 12, although the concentrations of both precursors were increased to $3: 30,7: 70$ and 10:100, the diameter size and the PDI value for these samples remain the smallest.

The doping concentration of thulium ions should be high in order to allow for high absorption of light at a pump wavelength and also to increase the quantum efficiency while the thulium ions clustering should be avoided to prevent the cooperative upconversion and quenching processes.

\section{Conclusion}

The synthesis methods reported had successfully synthesized thulium doped alumina nanoparticles using different concentration of precursors by using sol-gel method. A total of 28 samples were made and characterized to investigate the characteristics of the solutions. According to EDS, the element compositions inside the solutions are homogeneous. It has low counts of thulium-alumina and deduced to be little clustering happening at the samples. Results from FESEM showed that the particle size is within the nanoscale range at about $20-30 \mathrm{~nm}$ in diameter and more uniformly sized and structured. When concentration ratio of $\mathrm{Al}$ : $\mathrm{Tm}$ is $10: 1$, the particle size are the smallest compared to other concentrations. Jackson and Mossman (2003) suggested that a minimum $10: 1$ ratio of $\mathrm{Al}_{2} \mathrm{O}_{3}: \mathrm{RE}_{2} \mathrm{O}_{3}$ is necessary for complete dissolution of RE ions in silica glass.

\section{Acknowledgement}

The authors would like to acknowledge the support from the Faculty of Engineering, Multimedia University, 63100 Cyberjaya, Malaysia for supporting the project activities.

\section{Funding Information}

This project is funded by Ministry of Higher Education (MOHE) through the Fundamental Research Grant (FRGS/MMUE-140051).

\section{Author's Contributions}

Nur Atiqa Bt Rahmat: Drafted the article and conducted the experiments.

Hairul Azhar Abd Rashid: Define the method of investigation of the project.

H.Y. Wong: Reviewed and co-investigator of the project and the article.

Mukter Zaman: Principle investigator of the project, supervised the project, student and the article.

\section{Ethics}

The present work is not published in its present form in any journal or will not be published in any journal.

\section{Reference}

Desurvire, E., 1994. Erbium-Doped Fiber Amplifiers: Principles and Applications. 1st Edn., Wiley, New York, ISBN-10: 0471589772, pp: 800. 
Desurvire, E., 1995. Erbium-doped fiber amplifiers: Principles and applications. Phys. Today, 48: 56-56. DOI: $10.1063 / 1.2807915$

Honzatko, P., A. Dhar, I. Kasik, O. Podrazky and V. Matejec et al., 2012. Preparation and characterization of highly thulium- and aluminadoped optical fibers for single-frequency fiber lasers. Cornell University Library. DOI: 10.1117/12.912536

Blanc, W., T.L. Sebastian, B. Dussardier, C. Michel and B. Faure et al., 2008. Thulium Environment in A Silica Doped Optical Fibre. J. Non-Crystalline Solids, 354: 435-439.

DOI: $10.1016 /$ j.jnoncrysol.2007.06.083

Schmidt, H.K. and E. Geiter, 1998. The sol-gel process for nano-technologies: New nanocomposites with interesting optical and mechanical properties. J. Sol-Gel Sci. Tech., 13: 397-404.

DOI: $10.1023 / \mathrm{A}: 1008660909108$
Jackson, S.D. and S. Mossman, 2003. Efficiency dependence on the $\mathrm{Tm} 3+$ and $\mathrm{Al} 3+$ concentrations For Tm3+-doped silica double-clad fiber lasers. Applied Optics, 42: 2702-2707. DOI: 10.1364/AO.42.002702

Costa, V.C., M.J. Lochhead and K.L. Bray, 1996. Fluorescence line-narrowing study of $\mathrm{Eu}^{3+}$-doped sol-gel silica: Effect of modifying cations on the clustering of $\mathrm{Eu}^{3+}$. Am. Chem. Society, 8: 783-790. DOI: $10.1021 / \mathrm{cm} 9504910$

Alcatel-Lucent, 2007. Alcatel-Lucent achieves a world record 25.6 terabit/s optical transmission.

Deguchi, S., S. Mukai, M. Tsudome and K. Horikoshi, 2006. Facile generation of fullerene nanoparticles by hand-grinding. Adv. Mater., 18: 729-732. DOI: 10.1002/adma.200502487 